\title{
Rodent Nomenclature Name
}

National Cancer Institute

\section{Source}

National Cancer Institute. Rodent Nomenclature Name. NCI Thesaurus. Code C41105.

Official nomenclature name for mouse and rat models. 